\title{
Pepsinogen I Measurement
}

National Cancer Institute

\section{Source}

National Cancer Institute. Pepsinogen I Measurement. NCI Thesaurus. Code C100467.

The determination of the amount of pepsinogen I present in a sample. 